\title{
Natureza e artefato: laboratório como teatro de operações e manipulações materiais ${ }^{1}$
}

\author{
Maurício de Carvalho Ramos \\ maucramos@yahoo.com.br \\ Universidade de São Paulo, São Paulo, Brasil \\ Ronei Clécio Mocellin \\ r.cleciomocellin@gmail.com \\ Universidade Federal do Paraná, Curitiba, Brasil
}

«Les chimistes ont coûtume de designer ce double théatre de leurs spéculation par les noms de laboratoire de la nautre \& de laboratoire de l'art $\gg^{2}$

Venel

Resumo: Neste artigo propomos abordar a relação entre os conceitos de natureza e de artefato a partir de uma racionalidade química e alquímica. Pretendemos mostrar que essa racionalidade é originariamente tecnocientífica e apontar o modo como alquimistas e químicos construíram um quadro conceitual ancorado no laboratório do químico e no laboratório do orgânico. Nosso propósito é explicitar as transgressões e a capilaridade tecnocultural dos materiais criados nos laboratórios, bem como da existência de um estilo químico de raciocinar com suas particularidades ontológicas, epistemológicas e metodológicas.

Palavras-chave: natureza, artefato, química, alquimia, tecnociência, estilo de raciocínio.

Abstract: In this article we propose to treat the relation between the concepts of nature and artifact from a chemical and alchemical rationality. We intend to show that this rationality is originally technoscientific and to point out the way alchemists and chemists built a conceptual board anchored in the laboratory of the chemical and in the laboratory of the organic. Our proposal is to explain the transgressions and technocultural capillarity of the materials created in the laboratories, as well as the existence of a chemical style of reasoning with its ontological, epistemological and methodological particularities.

Keywords: nature, artifact, chemistry, alchemy, technoscience, style of reasoning.

\section{INTRODUÇÃO}

É de longa duração a história dos conceitos de natureza e de artefato. As questões centrais dessa história giram em torno das relações (ontológica, epistemológica, metodológica) existentes entre coisas ou substâncias que existem naturalmente e aquelas que são resultado de uma arte e que só existem por meio de uma ou de mais operações técnicas. Aqui, não propomos uma investigação geral desses conceitos e da polissemia de seus significados. Ao contrário, nosso propósito consiste em abordá-los a partir de um território de saber limitado e específico, aquele da química e da alquimia.

Trata-se não somente de explicitar alguns aspectos de uma racionalidade química que articulava a relação entre produtos naturais e artefatos (vivos ou inertes), como também de apontar o modo como alquimistas e químicos construíram um quadro conceitual ancorado em procedimentos experimentais, técnicos e industriais. A racionalidade que emerge desses territórios de investigação parece-nos originariamente técnica. Quanto à complexa relação entre a tradição alquímica e a "química acadêmica" que começava a se estruturar na hierarquia socioprodutiva do século XVIII, limitamo-nos a demonstrar 
a continuidade conceitual em torno da tecnicidade das operações químicas. Em relação a essa "química acadêmica" emergente, restringiremos nossa análise ao contexto francês e à descrição da produção de uma substância específica, a soda. Neste caso, o propósito é o de destacar as transgressões e a capilaridade tecnocultural dos artefatos criados nos laboratórios químicos.

A metáfora do teatro era de uso comum nas culturas científicas dos séculos XVII e XVIII e tinha interpretações variadas. Do mecanismo invisível evocado por Bernard de Fontenelle em seu Entretiens sur la pluralité des mondes (1686) ao conselho de não ultrapassar os limites da exterioridade expresso pelo abade Noël-Antoine Pluche em seu Spetacle de la nature (1732-1742, 9 volumes e numerosas reedições), a analogia entre o espetáculo da natureza e das artes era tão ampla quanto ambígua. Porém, o conceito de operação química permitia ultrapassar o escopo da simples metáfora, pois possibilitava a efetiva manipulação dos atores que entravam em cena tanto no teatro da natureza quanto no teatro do químico. A natureza seria ela mesma um teatro de operações, um laboratório químico-orgânico. As operações químicas não diferiam das operações da natureza senão pela capacidade reduzida dos utensílios dos químicos em seus laboratórios face ao imenso poder disponível no laboratório do mundo natural. Mas ambas agiriam no nível dos mixtos, com a ajuda do fogo, dos dissolventes (menstrues), e de todos os instrumentos químicos (BENSAUDE-VINCENT, 2003).

Por certo, as operações realizadas pelos químicos em seus laboratórios, submetidas a seu controle, podiam ser descritas de modo mais objetivo do que aquelas empregadas no laboratório do orgânico. No teatro do químico o papel dos atores era mais bem conhecido do que daqueles que atuavam no teatro da natureza. Com esta aproximação, pretendemos precisar nossa hipótese de continuidade conceitual entre alquimia e química demonstrando a equivalência técnica das manipulações realizadas em dois laboratórios: o do químico e o do orgânico.

Não existe ciência química sem laboratório químico. Para um químico, o laboratório nunca foi um gabinete de curiosidades ou um espaço de demonstração de leis naturais, mas um lugar onde ocorrem transformações, onde se articulam e relacionam não apenas os componentes íntimos da matéria, mas diversos níveis da estrutura social. O laboratório químico sempre foi um verdadeiro teatro de operações e manipulações materiais. $\mathrm{O}$ conhecimento químico pode mesmo ser caracterizado como um estilo de raciocinar cuja racionalidade se fundamenta em um espaço epistêmico específico de produção e de criação de teorias e de artefatos (BENSAUDE-VINCENT, 2009, pp. 365-378).

O laboratório do orgânico possui, por sua vez, uma forma mais geral ou "genérica" de operacionalidade, que pode se expressar de inúmeras formas específicas e em contextos históricos e tecnocientíficos variados. No contexto abordado, desejamos apenas apontar suas atividades gerais e que quando se passa do laboratório do químico para o laboratório do orgânico, conhecer o mundo material implica produzir vida artificial. Era nisso que consistia essencialmente a operação orgânica. Quer dizer, o nível específico de materialidade era o do orgânico, mas ele diferia do químico apenas em grau.

Assim, consideramos que o vínculo forte entre a existência de uma ciência e seu laboratório também se mantém para a esfera do orgânico. Mas, dada a tendência a certo desprendimento psíquico e "vibracional" da matéria viva, os produtos do laboratório orgânico são mais etéreos e a inteligibilidade do que era produzido escapa, em alguma medida, a uma racionalidade laboratorial pura. Enfim, dadas suas peculiaridades, a "descrição" dos componentes do laboratório do orgânico assume a forma de uma narrativa acerca de algumas operações gerais com as quais se poderiam manipular as entidades do mundo natural.

\section{TERRITÓRIO DE TRANSGRESSÕES}

Em janeiro de 1737, Henri Louis Duhamel du Monceau (1700-1782), químico-adjunto da Academia de Ciências de Paris e grande especialista em várias artes e ofícios, apresentou a seus pares uma dissertação com os resultados de uma série de experiências "sobre a base do sal marinho" (DUHAMEL DU MONCEAU, 1739, pp. 215-232). Segundo ele, esses resultados demonstravam o isolamento de umálcali fixo que entrava na composição do sal marinho e que esta "base" era indistinguível daquela extraída do natron e da soda. Demonstravam ainda que o sal marinho obtido da combinação desse álcali com ácido marinho era idêntico ao colhido nas salinas, e que esta "base" produzia sais diferentes daqueles formados pelo álcali obtido pela análise do sal de tártaro ${ }^{\text {. }}$

Os historiadores da química não se esqueceram de ressaltar a precisão desses experimentos, nem de 
apontar que as investigações de Duhamel du Monceau sobre a "base" do sal comum remetiam à produção artificial de soda, um material de grande aplicação industrial (vidro, têxteis, sabões), cujos procedimentos químicos necessários à sua obtenção somente seriam controlados por Nicolas Leblanc (1742-1806), em 1791 (VIEL, 2000). Porém, sua dissertação nos ajuda também a desvelar alguns traços que caracterizavam a operacionalidade tecnoconceitual que organizava a racionalidade do conhecimento químico no século das Luzes.

O tema dessa dissertação nos indica o terreno de pesquisa a que seu autor se dedicava. Seguindo um programa instituído na Academia por Wilhem Homberg (1652-1715), Etienne-François Geoffroy (1672-1731) e Louis Lémery (1677-1743) no início do século, as investigações de Duhamel du Monceau estavam no domínio da chamada química dos sais. Redefinidos, os sais deixavam de representar um princípio salino, manifestado pela solubilidade, e passavam a ser classificados como álcalis, ácidos e neutros ou médios. Isso abria um vasto campo de pesquisa, pois um sal podia ser considerado agora a partir de certo número de relações possíveis, seja com outros sais, seja com dissolventes (BENSAUDEVINCENT \& STENGERS, 1996, pp. 81-86).

Duhamel du Monceau começa sua narrativa frisando um dos conceitos centrais da trama conceitual da química da primeira metade do século, bem como o método experimental empregado para obtê-lo empiricamente. "Em química, diz ele, contamos bem conhecer um Mixto quando chegamos a separar os diferentes materiais que o compõem e, após ter examinado cada um em particular para bem conhecer sua natureza, sabemos reuni-los de tal maneira que eles se recompõem novamente, formando um corpo semelhante àquele que tínhamos, por assim dizer, anatomizado" (DUHAMEL DU MONCEAU, 1739, p. 215).

A noção de mixto foi introduzida na química do século XVIII pelo médico-químico Georg E. Stahl (1659-1734) que pretendia distinguir a união agregativa da união mixtiva (DUHEM, 1985). A primeira levava à produção de um agregado mecânico, formado a partir da reunião de partes iguais, enquanto a segunda produzia um composto químico, formado a partir da combinação de diferentes princípios ou elementos naturais. Esta diferença foi retomada por Gabriel-François Venel (1723-1775), autor do verbete Mixte \& Mixtion da Enciclopédia, ao afirmar que a

mixtion se faz pela justaposição, pela adesão das superfícies dos princípios, enquanto a agregação se faz por simples adesão das partes integrantes de indivíduos químicos. (...) A mixtion somente se exerce, ou se manifesta, entre as partes solitárias, únicas, individuais dos princípios, fit per mínima (...). A coesão mixtiva é muito intensa, o enlace que mantém os princípios dos mixtos unidos é muito forte, ele resiste a todas as potencias mecânicas. (VENEL, 1765, pp. 585-588)

Cabia então à química investigar as diferentes espécies de mixtos presentes nos três reinos naturais. A concretude material desses materiais somente se tornava possível através de análises químicas. Em termos gerais, "os químicos entendem pela palavra análise a decomposição de um corpo ou a separação dos princípios e partes constituintes de um composto” (MACQUER, 1766, t. 1, pp. 138-142). Contudo, na prática química, o que contava realmente eram os meios técnicos empregados para decompor amostras em seus constituintes.

Os processos analíticos seriam, simultaneamente, instrumentais e conceituais, pois articulavam a escolha da aparelhagem a ser utilizada e o nível da intervenção material pretendida. A análise química agia nos mixtos e, por isso, constituía um dos objetivos das operações químicas. Venel nos esclarece que "as operações propriamente e essencialmente químicas são aquelas que se executam através de instrumentos propriamente e essencialmente químicos”. Esses instrumentos eram o calor e os dissolventes (menstrues) que operavam na "união e na separação dos sujeitos propriamente e essencialmente químicos" e possibilitava conhecer os "corpúsculos das partes primitivas e quimicamente constitutivas dos corpos". A análise química (separar - diacrise) representa um sentido da operação química, porém o conhecimento efetivo de um mixto exigia o sentido inverso, ou seja, a síntese química (unir - syncrise) (VENEL, 1765, pp. 499-501).

Assim, a noção de operacionalidade constituía uma das formas de caracterizar os objetivos da ciência química das Luzes. A operação química, além de ser o meio pelo qual o químico manipulava os materiais, permitia uma reorganização do próprio conhecimento. Neste caso, foram exemplares as pesquisas sobre os sais desenvolvidas na Academia de Ciências de Paris e que teve na Tabela de relações Geoffroy uma 
síntese pedagógica e um terreno de pesquisa (HOLMES, 1989, pp. 33-60).

Independentemente da interpretação epistemológica dada a essa Tabela, o que contribui à nossa compreensão de uma racionalidade química está no fato de que ela operava efetivamente como um instrumento, ao mesmo tempo, pedagógico e conceitual. O conhecimento químico que emergia dessa Tabela não se fundamentava em axiomas ou princípios teóricos hipoteticamente pensados, mas em processos relacionais. Isso fazia com que a ciência química delimitasse seu território de atuação, um domínio que justificava uma ontologia, uma epistemologia e uma metodologia operacional que identificavam um tipo particular de conhecimento da materialidade do mundo (KLEIN, 1995).

Ademais, esses conceitos apontavam para a indiferença quanto à origem de um material. Obtido no laboratório do químico ou extraído diretamente da natureza, os materiais eram identificados por propriedades conhecidas unicamente por meio de seu comportamento químico. Seria possível fabricar no laboratório sais análogos aos encontrados na natureza? A química transgredia os limites da clássica divisão que opunha o natural ao artefato? Esta era justamente a questão de fundo presente na dissertação de Duhamel du Monceau. Seus resultados demonstravam que não havia nenhuma diferença entre o sal marinho artificial e o natural, ou seja, do ponto de vista da química, a fronteira entre natureza e artefato começava a ser superada (BENSAUDE-VINCENT, 2003, pp. 155-174).

Embora a tradicional divisão da natureza em reinos (mineral, vegetal e animal) ainda fosse largamente utilizada pelos manuais da época, os químicos também aspiravam construir uma teoria das afinidades capaz de unificá-los. As qualidades de um corpo não representavam a manifestação de algum princípio portador de qualidade, mas eram o resultado do arranjo material permitido pelas relações de afinidade. Todavia, isso não significava uma redução das especificidades de cada reino à química, tão pouco a desconsideração de suas particularidades operatórias, mas apontava para uma transversalidade das operações químicas entre os reinos naturais, o que possibilitaria a circulação material entre eles. A operação de vitrificação servia como demonstração concreta das relações entre os três reinos. Encontrado na natureza, um vidro era classificado como um mineral, mas quando o mixto vítreo era obtido artificialmente, ele era considerado uma síntese dos três reinos e indistinto do vidro natural (SIMON, 1999).

Com efeito, a especificidade da química estava em seu caráter operacional. Por isso, a filosofia experimental desenvolvida por Diderot encontrou forte apoio na ciência química apresentada na Enciclopédia por seu amigo Venel. Para Diderot, a filosofia experimental era uma maneira de se perguntar quais eram as práticas do saber e de onde elas procediam. Daí justamente a grande atenção dada por ele às artes, às ciências experimentais, ao saber-fazer. A química não era um simples modelo exterior a uma filosofia criada além de seus domínios. Na verdade, a convergência entre a filosofia experimental defendida por Diderot e a química estava na tentativa de desenvolver uma autêntica teoria a partir de um conhecimento prático e operacional da natureza (PEPIN, 2012).

Portanto, o experimentalismo e a operacionalidade da química do século das Luzes fizeram emergir uma prática científica cujos conceitos somente tinham sentido caso pudessem ser reconstruídos no laboratório. Os conceitos químicos não eram puramente teóricos nem simplesmente empíricos; eles eram na verdade um hibrido entre teoria e prática, um mixto conceitual. $\mathrm{O}$ traço comum entre a química e as demais artes era o de que seus conhecimentos eram construídos a partir de uma técnica, de um método experimental organizado com a finalidade de produzir um artefato estável. Como a operação química atingia o nível mais elementar, a química era a ciência que se ocupava efetivamente dos materiais, pois os estudava a fim de manipulá-los e de torná-los disponíveis. Quer dizer, a tecnicidade era intrínseca ao conhecimento químico (KLEIN \& LEFÈVRE, 2007).

Essa tecnicidade que se iniciava no nível mais básico de materialidade, articulava-se com outros níveis de organização material, pois os artefatos químicos eram muitas vezes produzidos em escala industrial. Mas, independentemente da ordem de grandeza, a produção de materiais de maneira controlada e metodicamente organizada era uma prática socialmente estruturada, envolvendo trabalhadores de diferentes ocupações, químicos treinados, industriais, além dos interesses de Estado. Ou seja, os artefatos que saiam, fossem de um laboratório de academia ou de um ateliê industrial, eram socialmente produzidos e tinham grande importância econômica. Assim, a articulação entre diferentes níveis de manipulação de corpos químicos e de materiais faz da química uma ciência eminentemente tecnocientífica (LEFĚVRE, 2005, pp. 194-225). 
A química deixava de lado a distinção hierarquizante entre teoria e prática, entre razão e experiência, pois conhecer o mundo material significava dominar as técnicas operatórias empregadas pelos químicos. Uma racionalidade química emergia de uma cultura comunitária, de um modo de pensar e de agir criado a partir de um nível específico de materialidade. Esta racionalidade estava absolutamente atrelada ao seu lugar de construção, ao espaço físico e epistêmico indispensável ao fazer química.

\section{LABORATÓRIO DO QUÍMICO}

Como a química é uma ciência ancorada na experiência, aqueles que desejam estudá-la devem aprender a refazer eles próprios os experimentos, para tornar sensíveis os conceitos utilizados pelas teorias químicas. Para se tornar um químico, alertava Pierre-Joseph Macquer (1718-1784), era absolutamente indispensável dispor de um laboratório equipado com todos os instrumentos e materiais para realizar as operações próprias desta ciência (MACQUER, 1778, t. 2, pp. 1-9). Bem antes deste sine qua non pedagógico de Macquer, alquimistas e químicos já consideravam que as abstrações teóricas eram desprovidas de significado caso não pudessem ser sentidas em um espaço físico específico, um lugar de trabalho (labor) provido dos meios materiais e humanos capazes de agir sobre as substâncias (PRINCIPE, 2013).

Em seu laboratório, Duhamel du Monceau se propunha a manipular diversas substâncias químicas e contava com a ajuda de eficientes instrumentos tecnoconceituais. A sequência de operações escolhidas pelo químico era a garantia dada por ele da fidelidade de suas conclusões. Os historiadores da química apontam, contudo, que o produto obtido por Duhamel du Monceau estava longe de ser uma soda aproveitável comercialmente. Ainda assim, vale destacar que a ordem operacional e a maioria das substâncias por ele empregadas apontavam a direção para se produzir soda artificialmente. Além disso, a informação técnica por ele descoberta - a "base" da soda era igual à do sal comum - foi extremamente pertinente (MAAR, 2008, p. 679).

"Uma operação de química das mais comuns, diz Duhamel du Monceau, pareceu-me fornecer uma via simples e natural para chegar ao que me propunha (...). Ela está fundada na propriedade do ácido vitriólico de combinar-se com matéria gordurosa para formar enxofre. Agora eis aqui a via que segui.... O primeiro passo consistia em adicionar certa quantidade de ácido vitriólico ao sal marinho, o que resultava na formação de sal de Glauber. A seguir, este sal era misturado com carvão em pó (fonte de matéria gordurosa) e calcinado em um cadinho (creuset) aberto, o que produzia um hepar sulphuris. Isto servia para diminuir no sal de Glauber a relação entre o ácido vitriólico e o álcali, "pois é bem conhecido que o ácido vitriólico tem mais ou menos a mesma relação com materiais inflamáveis e com sais álcalis" Ao hepar sulphuris era então adicionado o ácido do vinagre, o que servia para destruir a relação do álcali com o ácido vitriólico e criar uma nova relação, agora com a "base" do vinagre. Em seguida, este novo composto deveria ser calcinado até que resultasse apenas um sal álcali, "de modo que, por esta sequência de processos, julgo ter obtido a base do sal marinho, isolado e separado de toda outra base (DUHAMEL DU MONCEAU, 1739, p. 224)" 5 .

O modo tradicional de se produzir soda era a partir das cinzas de plantas marinhas. Porém, ao longo do século XVIII a demanda por soda na fabricação de vidros, de porcelanas, de sabões, de papel ou na lavação de tecidos tornava urgente que, de um ponto de vista econômico e estratégico, um reino se tornasse autossuficiente na produção deste material. O reino francês não o era e dependia da importação da soda produzida no reino da Espanha (soda de Alicante). Em 1766, trinta anos após Duhamel du Monceau ter exposto seus resultados, Macquer lamenta que "embora vários bons químicos tenham trabalhado detalhadamente na análise destes materiais, ainda restava muito a ser feito para se conhecer a exata proporção das diferentes matérias salinas e terrosas que entravam na composição das sodas" (MACQUER, 1778, t. 2. pp. 421-423).

Essa dificuldade do químico em manipular com suas operações e instrumentos certas substâncias a fim de produzir outras converge, no caso da soda, para necessidades em outros níveis de organização social. O caminho indicado por Duhamel du Monceau era muito interessante, pois se partia de um material relativamente abundante e barato (sal comum) e se chegava a um sal raro e caro (soda). Em 1783, a Academia de Ciências de Paris estabeleceu um prêmio para quem desenvolvesse um método economicamente viável para a obtenção artificial da soda. O prêmio será concedido apenas no final da década e o vencedor foi Leblanc, cujo método repetia as duas primeiras etapas do processo de Duhamel du Monceau'. 
O processo desenvolvido por Leblanc cumpria dois dos objetivos principais: partia de materiais relativamente baratos (sal, carvão e calcário) e tinha bom rendimento, o que apontava para seu emprego em escala industrial. Este método passou a ser amplamente utilizado, constituindo uma das origens da produção de substâncias químicas em grande escala. Quando a produção de ácido vitriólico (sulfúrico) começou a baratear, o método de Leblanc tornou-se hegemônico e, em 1870, existiam cerca de 40 fábricas ao redor do mundo produzindo soda artificialmente a partir deste procedimento experimental. Esta nova técnica industrial estendia a técnica operatória do laboratório do químico (MAAR, 2008, p. 716).

O entrelaçamento entre essas esferas de produção caracteriza, assim, outro aspecto "tecnocientífico" da ciência química. Das operações realizadas no laboratório de Duhamel du Monceau à escala industrial do método de Leblanc, a química se identifica como a ciência que explica e possibilita certas relações materiais, em diferentes ordens de grandeza. É também a ciência que subverte a separação entre "produtos naturais" e artefatos, entre teoria e prática. Trata-se também de um conhecimento de grande interesse público e frequentemente associado a objetivos produtivos, civis ou militares. Por isso, podemos considerar que a química do século XVIII aprofunda uma característica fundamental desta ciência, a sua tecnicidade originária.

Esse caráter tecnocientífico particular da racionalidade química se manifesta desde as primeiras ações do químico em seu laboratório, até a produção industrialmente organizada de artefatos químicos. Um caráter epistemológico distintivo desse conhecimento estaria, assim, no poder de ação dos químicos sobre os materiais com que trabalham e sua capacidade de colocá-los em relação através de operações técnicas controladas. Com isso, desde um ponto de vista químico, a fronteira entre "materiais naturais" e "materiais artificiais" começa a deixar de ter sentido, pois as substâncias químicas são tomadas não mais por sua origem, mas pelo que elas fazem. Além de transgredir esta fronteira conceitual de longa duração, a química do século das Luzes amplia consideravelmente a capacidade do homem de interferir no ambiente natural a fim de fabricar produtos economicamente desejáveis.

Essa intervenção técnica aponta enfim para a necessidade de se analisar suas implicações em outras esferas de interesse. No caso da soda, o domínio do processo artificial de sua produção não tinha somente efeitos positivos. Tal aspecto, aliás, parece ser uma característica dos artefatos produzidos pelo homem. Se nos modestos laboratórios do químico da primeira metade do século os resíduos descartados não tinham grande impacto, com a química industrial as coisas mudam. Os resíduos produzidos pelo processo de Leblanc, por exemplo, foram os responsáveis pelos primeiros desastres ambientais provocados pela indústria química. As operações químicas que poderiam tentar resolver esses problemas focalizavam a recuperação dos produtos secundários e sua possível manipulação para outros fins. As soluções químicas viriam do laboratório do químico, porém, adotá-las ou não dependia de sua inter-relação com outras esferas sociais de poder.

\section{LABORATÓRIO DO ORGÂNICO}

O laboratório do orgânico também é um teatro de operações e manipulações materiais. Por certo, as teorias e os artefatos neles criados têm significados mais fluidos e livres comparativamente àqueles do laboratório do químico. Mesmo assim, é possível estabelecermos uma continuidade entre duas importantes produções cognitivas que contribuíram à extensão de uma racionalidade química ao território do orgânico: a produção alquímica de homúnculos e a gênese de árvores químico-orgânicas ${ }^{7}$.

A geração alquímica do homúnculo está baseada, tal como a produção de árvores químicas que veremos a seguir, em uma ontogenia epigenética e, como se trata da geração de um humano, o processo também poderia ser concebido como uma antropogenia alquímica. Não faltam qualidades espirituais e astrais nesse homúnculo organicamente gerado, mas elas estão em continuidade com a matéria orgânica sob a qual o alquimista opera em seu vaso digestor submetido a um doce calor.

Isso fica mais claro se refletirmos diretamente sobre a maneira pela qual Paracelso (1493-1541) concebe o homúnculo e os processos naturais que tornam sua existência possível. Para o autor, aqueles que dominam a arte médica e alquímica podem gerar muitos seres animais a partir da putrefação de diferentes ervas (PARACELSO, 1894, p. 122). A natureza também produz animais monstruosos, muitos deles dotados de venenos com diferentes graus de potências, tais como serpentes, sapos, rãs, aranhas e abelhas. Igualmente por putrefação, a arte engendra, no interior dos vasos laboratoriais, monstros 
dotados de formas maravilhosas ou horrendas, com muitas cabeças, pés e caudas. O basilisco é uma espécie de "monstro dos monstros", pois é uma serpente em cujos olhos há um veneno que "atua sob a imaginação, não muito diferentemente de uma mulher menstruada que, também possuindo veneno em seus olhos, olhando muito concentradamente em um espelho torna-o sarapintado e manchado". Entre a mulher e o basilisco há uma afinidade natural e, explica Paracelso, o primeiro "é produzido e cresce a partir da principal impureza de uma mulher, a saber, de seu sangue menstrual". Assim, é possível gerar tais monstros em um receptáculo de vidro contendo sangue e esperma que são putrificados sob a ação do calor brando que provém do esterco (PARACELSO, 1894, p. 123).

Por um processo similar, os homúnculos podem ser gerados. Paracelso parece não ter qualquer dúvida sobre a realidade do fenômeno, pois, diz ele, "embora tenha sido por um longo tempo realizada de forma mais oculta e sigilosa, não havia, entre alguns dos antigos Filósofos, nenhuma dúvida quanto a ser possível para a natureza e para a arte que um homem fosse gerado sem o corpo da fêmea e sem o útero natural". Em um laboratório renascentista do orgânico, os vasos de vidro próprios para a antropogênese química seriam úteros artificiais. Os homúnculos são claramente artefatos produzidos em tais laboratórios, nos quais, sob o controle do artífice, a arte Espagírica e os processos naturais operam em harmonia. Posto isso, podemos apresentar a já muitas vezes citada fórmula paracelsiana que contém uma definição operacional bem precisa de homúnculo. Porém, devemos compreender que tanto a fórmula como a definição possuem sua própria racionalidade e, assim, não cabe mais, dentro do rigor da epistemologia histórica, associá-las a qualquer forma de "superstição":

Deixe o sêmen de um homem apodrecer espontaneamente por quarenta dias em uma cucurbita selada, junto da mais alta putrefação do ventre de um equino, ou até que comece finalmente a viver, a mover-se e agitar-se, o que pode ser facilmente visto. Após esse tempo, ele, de certa forma, será como um ser humano, mas transparente e sem corpo. Entretanto, se, depois disso, ele for alimentado com arcano de sangue humano todos os dias, com cautela e prudência, e mantido por quarenta semanas permanentemente sob um calor uniforme igual ao do ventre de um equino, transformar-se-á em uma verdadeira criança vivente, contendo todos os órgãos de uma criança que nasce de uma mulher, sendo, porém, muito menor. É isso que chamamos homúnculo; ele deve ser depois educado com o maior cuidado e zelo, até que cresça e comece mostra-se inteligente (PARACELSO, 1894, p. 124).

Um homúnculo assim gerado será um homem artificial singular produzido em uma cucurbita que imitou as qualidades gerativas de um útero humano natural. Na narrativa ou exposição desse resultado há um conjunto muito expressivo de imagens e cenas que tornam o laboratório um teatro de operações e manipulações orgânicas. Deixaremos aos leitores julgar quão contemporâneo é (literalmente ou metaforicamente) o drama prometeico encenado.

A geração artificial de miniaturas humanas monstruosas conecta-se à produção de miniaturas de árvores químicas/orgânicas. Trata-se das famosas árvores metálicas geradas nos laboratórios de químicos franceses do início do século XVIII, que remetem ao solo da cultura científica em que nasceu o pequeno laboratório domiciliar de Duhamel du Monceau. Tal como fizemos para o homúnculo, segue-se a fórmula para a produção de alguns exemplares dessas árvores singulares feita à base de ferro:

Quando vertemos espírito de nitro sobre limalha de ferro, sabe-se que ocorre uma efervescência violenta acompanhada de um calor tão forte que é quase impossível colocar a mão sobre o recipiente. Após a efervescência, o líquido torna-se vermelho e carregado devido ao ferro que foi dissolvido. Eu coloquei óleo de tártaro sobre essa dissolução de ferro [...] e pouco tempo depois formou-se nas paredes do recipiente vários ramos pequenos bem distintos que, elevando-se sempre do líquido sem fermentação aparente e aumentando continuamente, logo alcançaram o topo do recipiente, chegando mesmo a cair para fora em tão grande quantidade que eles cobriram sua superfície interna e externa. Poderíamos dar o nome de árvore de ferro ou de marte a essa espécie de vegetação química. Como me pareceu curiosa, eu repeti esta experiência um grande número de vezes, tanto aumentando quanto diminuindo a dose de óleo de tártaro, e sempre se formaram diferentes tipos de vegetações que, às vezes, se pareciam apenas com puros ramos; frequentemente estes ramos estavam como que providos de folhas, acima, como que exibindo frutos ou flores e, abaixo, traziam ou filetes que imitavam perfeitamente a figura das raízes ou vasos realmente ocos que partiam do fundo do recipiente e se comunicavam com o topo, onde estava o grosso da vegetação (LÉMERY, 1706, pp. 414-5). 
Comparando o homúnculo de Paracelso e a árvore química de Louis Lémery, uma semelhança de ordem técnica logo se destaca: nos dois casos, trata-se de produzir artificialmente a forma ordinária de seres naturais por meio de operações que, em essência, reúnem artificialmente as condições necessárias para que elementos em um estado aparentemente mais simples de organização passem a um nível mais complexo e mais próximo dos existentes nos organismos originais. A mistura de sêmen e sangue humanos é análoga à mistura de limalhas de ferro e espírito de nitro; a cucurbita, que imita o útero humano e recebe a primeira mistura, corresponde ao recipiente que contém a segunda mistura; o movimento e a agitação que se verifica na primeira e a efervescência, com produção de calor, que ocorre na segunda, também estão muito próximas - diríamos que são duas espécies de putrefação fermentativa; o arcano de sangue e o óleo de tártaro que são posteriormente adicionados podem ser considerados como as substâncias nutritivas dos embriões em gestação; por fim, os órgãos animais da pequena criança correspondem aos órgãos da planta, a saber, seus ramos, folhas, frutos, flores e raízes. Numa comparação mais ampla dos produtos finais, teríamos, conceitualmente, duas cristalizações orgânicas como processos bem próximos, mas que diferem nos detalhes técnicos para sua imitação em laboratório (o tempo de gestação de cada cristaloide é uma diferença fundamental).

No laboratório do orgânico pode-se reproduzir controladamente os processos que atuam na produção natural dos corpos pertencentes aos reinos mineral, vegetal e animal. Na expressão desse laboratório no século XVIII, bem como em boa parte do campo conceitual da química moderna que lhe serve de fundo teórico, "explicações sustentadas empiricamente e experimentalmente para o difundido e já antigo postulado de que as plantas formam o segundo reino da natureza [...] é a chave para a passagem do inorgânico ao orgânico, do vivo ao não-vivo ou de pares conceituais que significam a mesma transição"(RAMOS, 2011, pp. 828-829). Cremos que a comparação do homúnculo com a árvore de marte que fizemos ajuda a esclarecer como se deram essas significativas transformações epistemológicas.

Considerações mais específicas podem ainda ser feitas quanto à produção das árvores metálicas. Para garantir a continuidade das metamorfoses do laboratório do orgânico no interior da cultura científica do século XVIII, tais árvores não devem ser concebidas apenas como semelhante a uma árvore viva. Elas possuiriam em comum certo "estofo" que as tornavam idênticas em sua dimensão genética (eram de mesmo gênero). Essas árvores diferiam em espécie não de modo descontínuo ou abrupto, mas como uma diferença de grau. Uma árvore de cobre, por exemplo, era apenas um pouco menos árvore do que um carvalho. A racionalidade da cadeia do ser aplicava-se aqui integralmente ${ }^{8}$.

Por fim, como dissemos, o laboratório do orgânico possui uma forma genérica. Neste sentido, dentre os vários produtos que o laboratório específico de Lémery sintetizou, a geração de árvores químicas metálicas seriam casos singulares de expressão desse laboratório geral do orgânico que, nesse período histórico da cultura científica, ainda não se concretiza na forma especializada de um laboratório de química orgânica. Nesse contexto, os laboratórios químico e orgânico estão ainda fundidos e, assim, é possível atribuir uma natureza dupla e igualmente fundida a algumas de suas produções especiais: a dos hipermixtos.

\section{CONCLUSÃO}

A química é a ciência que tradicionalmente transgrediu a dicotomia entre o natural e o artefato. Sua ambição prometeica não difere daquela dos alquimistas que, na justificação dos produtos de sua arte, evocavam sua capacidade de produzir artificialmente uma mimesis dos processos empregados pela própria natureza. Os termos natural e artefato significam coisas diferentes dependendo do contexto e do ponto de vista em que são empregados. Precisados esses contextos, a química (ou a alquimia) constitui uma porta de entrada privilegiada nesse debate filosófico de longue durée. Isto permite, por exemplo, uma aproximação de questões que permanecem comuns, tanto à produção de homúnculos e da soda quanto aos artefatos criados pela nanoquímica ou aos seres vivos modelados pela biologia sintética (NEWMAN, 2004).

Se no caso da criação do homúnculo dos paracelsianos a metáfora prometeica coloca um caso extremo (a criação de um homem), a produção de árvores químicas era bem mais próxima da realidade operacional do laboratório do químico. Esta produção estava no mesmo contexto conceitual e institucional no qual se dava a investigação sobre a química dos sais, de modo que sua analogia com uma árvore natural era mais objetiva. Isto nos permitiu não apenas analisar os processos operatórios envolvidos na produção de sais naturais nas bancadas do laboratório químico, mas também olharmos para outros níveis de absorção 
dos artefatos aí criados. Assim, procuramos focalizar com mais precisão as manipulações realizadas pelos químicos em seus laboratórios e a filosofia experimental a ela associada. A partir disso, propusemos um primeiro retrato da racionalidade das operações químicas que revela seu caráter tecnocientífico stricto sensu.

Radicalmente anti-essencialistas, os químicos das Luzes buscavam conhecer as sustâncias em função do que elas faziam e não a partir de alguma suposta essência elementar. Segundo Bernadette BensaudeVincent, o primado da relação sobre a substância e o princípio de ação da matéria eram duas características fundamentais da ontologia da química do século XVIII. Além das substâncias que constituem os corpos simples e complexos, o químico postulava a existência de seres individuais definidos pela sua capacidade de entrar em relação com outras entidades individuais. A razão de ser dos "corpos químicos" era a relação e a ação (BENSAUDE-VINCENT, 2008, pp. 51-64) .

Embora as entidades ou seres propriamente químicos pudessem ser manipulados no laboratório do orgânico, foi a partir do laboratório do químico que as relações e as ações entre os corpos químicos foram organizadas e classificadas. Os mixtos constituíam o nível básico de elementaridade que interessava aos químicos. As operações químicas articulavam tanto as descrições teóricas quanto as realizações práticas. Dessa maneira, tem-se um segundo retrato da racionalidade que governava a "Republica dos químicos" e que nos revela particularidades ontológicas, epistemológicas e metodológicas da ciência química.

A produção de um artefato específico, a soda, forneceu a oportunidade de refletir sobre os materiais que entram e que saem de um laboratório químico. Demos particular relevância ao fato de que o conhecimento químico é profundamente imbricado à indústria, e que isso engendra novas questões de interesse histórico e filosófico. Com isso apontamos para a disseminação sociocultural dos artefatos químicos; o que nos serviu com cenário de um terceiro retrato da racionalidade operacional da química das Luzes, que nos revela a capilaridade tecnocultural de seus artefatos.

Esses "retratos de racionalidade" próprios à química e a seus artefatos estão longe de esgotar os ângulos e perspectivas da ciência envolvida nos casos históricos aqui comentados. No entanto, sobretudo no caso da produção de materiais naturais ordinários (sais) ou de artefatos ausentes do meio natural, podemos concluir que os traços constitutivos da racionalidade química originam-se de uma característica específica desta ciência, a de ser um conhecimento construído em um "espaço-epistêmico" que lhe era próprio.

Em seus laboratórios, os químicos criaram um estilo de raciocinar, um modo de perceber, de pensar e de sentir os materiais (naturais ou artefatos) segundo uma lógica química. Enfim, tantos o laboratório do químico quanto o laboratório do orgânico constituem portas de entrada para o universo das transformações materiais e para uma plêiade de questões suscitadas por uma ambição prometéica, permanentemente metamorfoseada.

\section{NOTAS}

1. Este artigo é parte das atividades realizadas durante o pós-doutorado de Ronei Clécio Mocellin na Faculdade de Filosofia, Letras e Ciências Humanas da USP junto ao Grupo de Pesquisa em Epistemologia Histórica da Cultura Científica, com supervisão do professor Maurício de Carvalho Ramos. Trabalho realizado com bolsa concedida pela FAPESP.

2. Venel, G-F. Verbete "Chymie", in Encyclopédie ou Dictionnaire Raisonné des Sciences, des Arts et des Méties. Nouvelle impression en facsimilé de la première éditon. Stuttgart-Bad Cannstatt: Verlag, 1967, t. 3 (1753), p. 410.

3. Em nomenclatura moderna: álcali fixo (hidróxido de sódio - $\mathrm{NaOH}$ ); sal marinho (cloreto de sódio - $\mathrm{NaCl}$ ); natron (carbonato de sódio deca hidratado $-\mathrm{Na}_{2} \mathrm{CO}_{3} \cdot 10 \mathrm{H}_{2} \mathrm{O}$ ); soda (carbonato de sódio - $\mathrm{Na}_{2} \mathrm{CO}_{3}$ ); ácido marinho (ácido clorídrico - $\mathrm{HCl}$ ); sal de tártaro (carbonato de potássio $-\mathrm{K}_{2} \mathrm{CO}_{3}$ ).

4. Duhamel du Monceau, op. cit. p. 223.

5. Algumas das substâncias utilizadas nas operações de Duhamel du Monceau: Ácido vitriólico (ácido sulfúrico - $\mathrm{H}_{2} \mathrm{SO}_{4}$ ); $\mathrm{Sal}_{\text {de }}$ Glauber (Sulfato de sódio - $\mathrm{Na}_{2} \mathrm{SO}_{4}$ ); hepar sulphuris (mistura de compostos de enxofre $-\mathrm{S}_{8}, \mathrm{Na}_{2} \mathrm{~S} .$. ); ácido do vinagre (ácido etanóico - $\mathrm{CH}_{3}-\mathrm{COOH}$ ); sal álcali fixo (carbonato de sódio $-\mathrm{Na}_{2} \mathrm{CO}_{3}$ ). 
6. Resumidamente e em linguagem moderna o "processo Leblanc" consiste nas seguintes etapas:

1a) $2 \mathrm{NaCl}+\mathrm{H}_{2} \mathrm{SO}_{4} \rightarrow \mathrm{Na}_{2} \mathrm{SO}_{4}+2 \mathrm{HCl}$;

2a) $\mathrm{Na}_{2} \mathrm{SO}_{4}+2 \mathrm{C} \rightarrow \mathrm{Na}_{2} \mathrm{~S}+\mathrm{CO}_{2}$;

3a) $\mathrm{Na} \mathrm{S}+\mathrm{CaCO}_{3} \rightarrow \mathrm{Na}_{2} \mathrm{CO}_{3}+\mathrm{CaS}$;

Reação global: $2 \mathrm{NaCl}+2 \mathrm{C}+\mathrm{CaCO}_{3}+\mathrm{H}_{2} \mathrm{SO}_{4 \rightarrow} \mathrm{Na}_{2} \mathrm{CO}_{3}+\mathrm{CaS}+\mathrm{CO}_{2}+2 \mathrm{HCl}$.

7. Para A. Debus, a nova filosofia natural dos séculos XVI e XVII utilizava a química como modelo para uma imagem de natureza ou de cosmo químico na qual Paracelso e os paracelsistas foram as figuras centrais. Eles opunham-se ao conhecimento aristotélico e galênico apresentando em seu lugar uma filosofia fortemente influenciada pela literatura neo-platônica cristã e hermética. Apesar de realizarem uma exegese bíblica sob uma perspectiva hermética, a orientação religiosa dos paracelsistas também reivindicava uma nova filosofia da natureza baseada em observações e experimentos. Rejeitando o método lógico-matemático, eles voltaramse para a química "com a convicção de que esta ciência poderia ser a base para um novo entendimento da natureza" (DEBUS, 1977, p. 76). A química passa a ser uma ciência com um campo universal. Para Paracelso a alquimia e a química "podiam ser utilizadas como chaves para decifrar o cosmo, seja mediante a experimentação direta, seja mediante a analogia” (PARACELSO, 1894, p. 55). Paracelso explicava a criação como uma revelação química da natureza. Acreditamos que é possível caracterizar uma espécie de criacionismo naturalizado no qual os eventos narrados do Gênese bíblico são interpretados à luz desta filosofia química. A criação de um homúnculo é consistente com tais concepções e refletem uma racionalidade alquímica coesa sob a fórmula do macro-microcosmo. Outro autor citado por Debus que expressa muito bem a mesma ideia de criação química é Thomas Tymme (d. 1620), para quem a criação foi uma extração, separação, sublimação e conjunção alquímicas. Processos identificados às transformações das substâncias no laboratório eram associados a transformações também de natureza química e alquímica que deram origem à terra, aos céus, às águas e, enfim, a todas as criaturas da natureza.

8. Isso mantém a cadeia do ser como elemento para a classificação, mas a anula geneticamente mostrando que é possível produzir organismos de um reino para o outro.

9. Acrescentamos aqui uma passagem de Substância e função na qual a interpretação cassireana da tabela de Geoffroy feita pela autora pode ser melhor apreciada. Em sua construção da evolução moderna dos conceitos em química, Cassirer afirma que, uma vez pressuposta a existência objetiva de diferentes tipos de átomos, foi necessário «descobrir suas 'propriedades' e então defini-las mais precisamente. Quanto mais posteriormente avançamos e mais diversos são os grupos de fenômenos que consideramos, muito maior peso devemos conferir a essas propriedades. A 'interioridade’ substancial do átomo é revelada e assume, para nós, uma forma fixa e tangível. Especialmente na constituição das fórmulas químicas mais evoluídas, identificamos como os átomos estão situados uns em relação aos outros e como estão mutuamente conectados na estrutura unificada da molécula. Em sua combinação, podemos ver que eles geram, em função de seu número e de sua posição relativa, um certo esquema estrutural, tal como é expressa, por exemplo, nas formas dos cristais» (itálicos nossos). Acrescentaríamos aqui que essa estrutura da molécula de onde brota a individualidade e a interioridade dos átomos, também pode ser precisamente concebida como uma forma relacional da qual a forma cristalina é uma expressão.

\section{REFERÊNCIAS}

BENSAUDE-VINCENT, B. 2003. La nature laboratoire. In : Rousseau et les Sciences. Paris: L'Harmattan. .2008. L'énigme du mixte. In Matière à penser. Essais d'histoire et de philosophie de la chimie. Paris:

Presses Universitaires de Paris Ouest. . 2009. The chemist's style of thinking. In: Berichte zur Wissenschaftsgeschichte, v. 32.

. \& STENGERS, I. 1996. História da química. Lisboa: Instituto Piaget.

CASSIRER, E. 1953. Substance and function and Einstein's theory of relativity. Chicago: Dover.

DEBUS, A. 1977. The chemical philosophy: paracelsian science and medicine in the sixteenth and seventeenth centuries. Mineola: Dover Publications.

DUHAMEL DU MONCEAU, H. D. 1739. Sur la base du sel Marin. In : Mémoires de l'Académie royale des sciences - Année 1736. Paris: Imprimerie Royale.

DUHEM, P. 1985 [1902]. Le Mixte et la Combination Chimique. Paris : Fayard.

HOLMES, F. 1989. Eighteenth-Century Chemistry as an Investigative Enterprise. Berkeley: office for the History of Science.

KLEIN, U. E.F. 1995. Geoffroy's Table of Different 'Rapports' Observed Between Different Chemical Substance - A Reinterpretation. AMBIX, vol. 42, 2.

. \& LEFĖVRE, W. 2007. Materials in Eighteenth-Century Science: A historical ontology.

Massachusetts: MIT Press.

LEFÈVRE, W. 2005. Science as labor. In: Perspectives on Science, v. 13, n 2. 
LÉMERY, L. 1706. Que les plantes contiennent réelement du fer, \& que ce métal entre necessairement dans leur composition naturelle. Mémoires de l'Académie Royale des Sciences. Paris: Imprimerie royale MAAR, J. H. 2008. História da Química, primeira parte. 2a ed. Florianópolis: Conceito Editorial. MACQUER, P.-J. 1766. Analyse. In Dictionnaire de Chymie. Paris: Lacombe.

NEWMAN, W. 2004. Promethean ambitions: alchemy and the quest to perfect nature. Chicago: University of Chicago Press.

PARACELSO. 1894. Arthur Edward Waite (Ed.) The Hermetic and Alchemical Writings, v. 1: Hermetic Chemistry. Londres: James Elliot.

PÉPIN, F. 2012. La philosophie expérimentale de Diderot et la chimie : Philosophie, sciences et arts. Paris: Garnier.

PRINCIPE, L. M. 2013. The Secrets of Alchemy. Chicago: The University of Chicago Press.

RAMOS, M. de C. 2011. Vegetações artificiais: palingênese, árvores metálicas e plasmogenia. In: Scientiae Studia, 9, 4.

SIMON, J. 1999. L'Homme de verre? Les trois regnes et la promiscuite de la nature. In : Corpus, revue de philosophie, 36. 